\title{
Risks associated with mother-to-child transmission of HIV infection
}

\author{
Félicitée Nguefack ${ }^{1,2}$, Paul Koki Ndombo ${ }^{1,3}$, Rose Ngoh $^{3}$, Florence Soh Fru ${ }^{2}$, Mina Ntoto \\ Kinkela $^{3}$, Andreas Chiabi ${ }^{1,2}$ \\ ${ }^{1}$ Department of Pediatrics, Faculty of Medicine and Biomedical Sciences, University of Yaounde I, Yaounde, Cameroon, \\ ${ }^{2}$ Yaounde Gynaeco-Obstetric and Pediatric Hospital, ${ }^{3}$ Mother and Child Center of the Chantal Biya Foundation. \\ E-mail: dongfel@yahoo.fr \\ Received: 8th May 2017, Accepted: 6th June 2017
}

SUMMARY: Nguefack F, Koki-Ndombo P, Ngoh R, Soh Fru F, Kinkela MN, Chiabi A. Risks associated with mother-to-child transmission of HIV infection. Turk J Pediatr 2017; 59: 426-433.

Early infant diagnosis (EID) permits the detection of Human Immunodeficiency Virus (HIV) infection in exposed children from 4-6 weeks by polymerase chain reaction (PCR). The aim of this study was to assess some maternal and infant characteristics associated with HIV infected children in an EID program.

A retrospective study was performed using records of HIV exposed children enrolled in the EID program from 2009 to 2013. Patients recruited were from various health structures and at different clinical stages; some for the Prevention of Mother-to-Child Transmission (PMTCT) follow up, others with signs of HIV infection. Data was collected from completed hospital records of children aged 6 weeks to 18 months containing at least two PCR, one PCR and one serologic test, or one PCR test and viral load. HIV infection was considered if one of the of tests was positive.

In all, $130(5.3 \%)$ exposed children with only one positive PCR test, and $1,442(59 \%)$ others with information lacking in their record were excluded. A total 107 out of 871 infants enrolled (12.2\%) were infected. Only, 32.7\% of the mothers were on antiretroviral therapy (ART). Of these, $53.3 \%$ had their first PCR performed between 6 weeks and 6 months. Children were less likely to be HIV infected when their mothers received antiretroviral (ARV) $(\mathrm{OR}=0.15,95 \% \mathrm{CI} 0.07-0.30, \mathrm{P}=0.000)$. Factors associated with HIV infection in the children were the lack of $A R V$ prophylaxis $(O R=2.07,95 \% \mathrm{CI}$ 1.05-4.09, $\mathrm{P}=0.035)$ and having mixed feeding $(\mathrm{OR}=3.91,95 \% \mathrm{CI} 1.66-9.24$, $\mathrm{P}=0.002$ ) in multivariate analysis.

The high rate of infection associated with the maternal and infant correlates of HIV infected children would result from the poor implementation of the PMTCT. Systematic screening of pregnant and breastfeeding women should be reinforced and the lifelong ARVs for PMTCT (Option B+) be promoted.

Key words: HIV, early infant diagnosis, infection, factors.

Pediatric human immunodeficiency virus (HIV) infection is most often acquired vertically from mother to child, either during pregnancy, delivery or breastfeeding. ${ }^{1,2}$ It has been noted that combined interventions including antiretroviral (ARV) prophylaxis, caesarean section and the use of formula feeding has reduced the risk of mother to child transmission of HIV (MTCT) in high resources setting up to a rate of less than 2\%.1-3 Meanwhile, in low resource settings such as ours, the implementation of such interventions is low because of multiple barriers ${ }^{4}$, so MTCT is still high with rates ranging from $3.6 \%$ to $15 \%$ where the Prevention of Mother-to-Child Transmission (PMTCT) program is not implemented.5-7 The lack of antiretroviral treatment during pregnancy is among the main risk factors for transmission identified in many studies. 8,9

Early infant diagnosis (EID) permits the 
detection of HIV infection in an exposed infant from 4-6 weeks by Polymerase chain reaction (PCR). ${ }^{10}$ It permits early initiation of ART in infected children and also helps to make decision concerning the follow up of uninfected HIV exposed children. ${ }^{11}$ Newell et al. ${ }^{12}$ noted that without any intervention, $35.2 \%$ of HIV infected children will die at the end of the first year in resource-limited settings, and the median survival of the infected infants was 23 months in Uganda. ${ }^{13}$ Because of the high risk of death and given the increasing availability of pediatric ART in resource-limited settings, WHO recommends that national programs should provide early virological testing of infants for HIV. ${ }^{11}$ In our milieu, the HIV status of most infants, born from infected mothers is frequently unknown at the early stage of life even though, EID of HIV is feasible. ${ }^{14}$ In Eastern Cameroon, it was noted that the median age at first HIV testing was 4 months with $91.1 \%$ of infants and $65.2 \%$ of their mothers not receiving any ARV prophylaxis. ${ }^{15}$ In a study at Yaounde, almost all mothers (98.2\%) were aware of the need for EID, but only $67.1 \%$ were informed about the test and $47.9 \%$ knew the appropriate time at which it should be done ${ }^{16}$.
The EID program provides an occasion for assessing the success of the implementation of PMTCT. ${ }^{17}$ This study aims at assessing some maternal and infant characteristics found in HIV infected children in the EID program implemented since 2007 at the Mother and Child Center of the Chantal Biya Foundation in Yaounde, Cameroon.

\section{Materials and Methods}

This was a retrospective study. The target population was HIV-exposed infants enrolled in the EID program from 2009 to 2013. Patients recruited were from various health structures and at different clinical stages; some for the PMTCT routine follow up, others with suspected signs of HIV infection, or for the management of an already diagnosed infection.

Completed files of HIV-exposed children aged 6 weeks to 18 months containing at least 2 PCR tests or at least 1 PCR and 1 HIV serology, or 1 PCR with viral load considered, defining their HIV status were included.

We collected information regarding the sociodemographic profile of the mother, history of pregnancy and delivery, ARV prophylaxis or

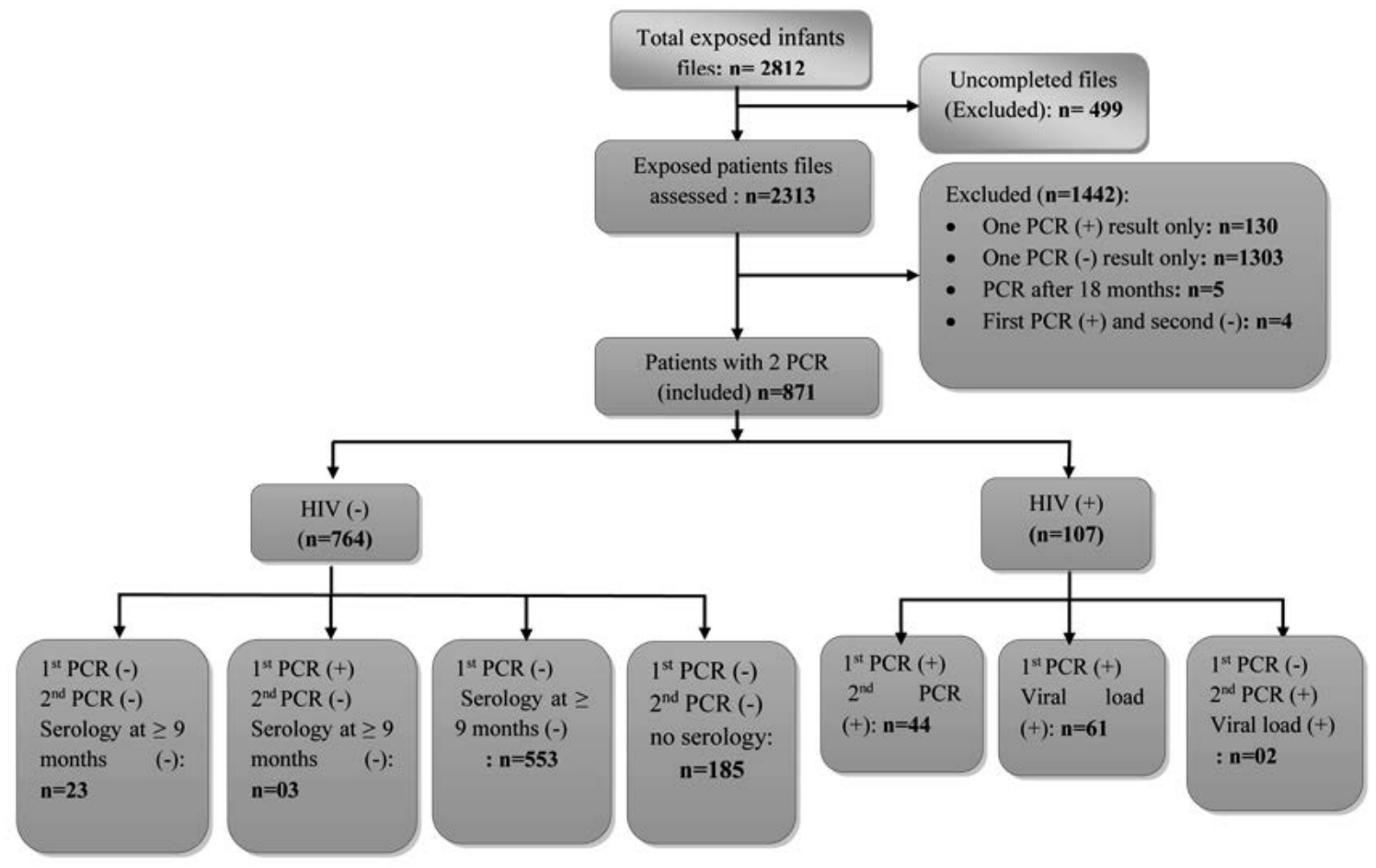

Fig. 1. Flow diagram of enrollment of patients in early infant diagnosis (EID) program 
Table I. Baseline Characteristics of the Mothers.

\begin{tabular}{llll}
\hline Maternal Characteristics & & Frequency & Percentage \\
\hline Age group (years) & $\leq 20$ & 12 & 11.2 \\
& $21-30$ & 66 & 61.7 \\
Marital Status & $31-40$ & 29 & 27.1 \\
& Cohabiting & 50 & 46.7 \\
& Single & 43 & 40.2 \\
& Married & 11 & 10.3 \\
Profession & Widow & 3 & 2.8 \\
& House wives & 57 & 53.3 \\
& Private sector & 34 & 31.8 \\
& Students & 10 & 9.3 \\
ARV during pregnancy $(\mathrm{N}=35)$ & Others & 6 & 5.5 \\
& ARV prophylaxis & 24 & 68.6 \\
& HAART before pregnancy & 10 & 28.6 \\
& Others & 1 & 2.8 \\
\hline
\end{tabular}

ARV: antiretroviral treatment; HIV: human immunodeficiency virus; HAART: highly active antiretroviral treatment; PCR: polymerase chain reaction

treatment received during pregnancy. Infant variables collected included the birth weight, PMTCT measures, age at first PCR, feeding option and HIV status. The ARV prophylaxis was considered according to the different national guidelines in use at the time of followup. At our study site, the first PCR-DNA was done at the age of 6 weeks. Whole blood was collected and transferred to the virology laboratory of Centre Pasteur of Cameroon (CPC) when the child was selected under the ANRS 12140-Pediacam survey. The others samples sent for analysis at the Chantal Biya International Reference Centre for Research (CBIRC) were collected onto filter papers (DBS) and processed according to standard procedures ${ }^{18}$ before transport to the laboratory. Occasionally viral loads were requested. Two PCR tests were required, and the first, if positive, was confirmed by a second before the exposed infant was declared HIV infected. For breastfed children, a second PCR was done at 6 weeks after complete cessation of breastfeeding ${ }^{19}$. The expected period for results to return was after 4 weeks. If positive, a second blood sample was collected for the second PCR and the infant was put on ART while waiting for confirmation. If the second PCR was positive, then the infant was declared HIV infected, and if it was negative, the third DBS sample was collected for the third PCR.
For infants who were breastfed, if the first and the second PCR performed after the cessation of breast feeding were all negative, the infant was declared not infected. In those on formula who had the first PCR and HIV serology negative the infant was also declared not infected. Two discordant PCR results required a third to have a definite status of the patient. The serologic test was performed above 12 months. When there was a discordant serology result, a PCR was done and the exposed uninfected infants exited the EID program. Infants were uninfected when they had negative PCR test results with/without HIV negative serology.

\section{Data analysis}

For HIV-infected children, we described the maternal and infant characteristics with continuous variables using means; or median with inter-quartile range and categorical variables using the percentages. Univariate then multivariate stepwise logistic regression analysis was used to determine the significant maternal and infant variables as independent correlates of infection in HIV infected children. The Fisher test and the Odds ratio with a confidence interval at $95 \%$ was used to determine the factors correlated with HIV infection in children at a p-value $<0.05$.

The study was approved by the Ethics 
Committee of the Faculty of Medicine and Biomedical Sciences of the University of Yaounde I.

\section{Results}

In all, 871 HIV exposed children were enrolled, amongst which 107 (12.2\%) were infected. We excluded 499 patients with only one positive PCR test, and 1,442 exposed children because information was lacking in their file (Fig. 1). The mothers of the infected children were aged $15-40$ years with a mean age of 27.3 years. Only $32.7 \%$ benefited from ARV treatment during pregnancy, and in only $68.6 \%$, ARV prophylaxis was given as recommended by the national guidelines (Table I). This consisted of single dose nevirapine (NVP) $(2 / 107)$, zidovudine (AZT) from 28 weeks of pregnancy $(5 / 107)$ and AZT from 28 weeks of pregnancy plus single dose NVP (17/107).

More than half $(53.3 \%)$ of the HIV infected children had their first PCR test done between 6 weeks to 6 months, while the median age was 21 weeks. Most of them (58.0\%) did not receive any ARV prophylaxis after birth (Table II). Feeding with formula was the most frequent option (43\%) compared to exclusive breastfeeding (29\%) and mixed feeding (28\%).

The maternal risk factors of having an infected infant were living single (OR 1.68, 95\%CI
$1.12-2.55, \mathrm{P}=0.009)$ and being less than 30 years old (OR 2.29, 95\%CI 1.51-3.49, $\mathrm{P}=0.000)$. Others factors were per vaginal (OR 2.95, 95\% IC 1.27-6.89, $\mathrm{P}=0.004$ ) and home delivery (OR 5.76, 95\%CI 2.36-14.01, $\mathrm{P}=0.000$ ). Infants of mothers on highly active antiretroviral therapy (HAART) were less likely to have HIV infection; compared with those whose mothers were on ARV prophylaxis (OR 0.22 , 95\%CI 0.11-0.45, $\mathrm{P}=0.000$ ); (Table III).

Factors related to the children were the PCR performed less than 6 weeks of the life, (OR 4.86, 95\%CI 2.67-8.83, $\mathrm{P}=0.000$ ) and mixed feeding (OR 24.52, 95\%CI 12.31-48.83, $\mathrm{P}=0.000)$. On the contrary, ARV prophylaxis at birth protected children against infection (OR 0.06, 95\%CI (0.04-0.09), $\mathrm{P}=0.000$ ); (Table IV).

\section{Factors associated with HIV infected children} in multivariate analysis

HIV infection in children was less frequent when theirs mothers received HAART (OR $0.3,95 \%$ CI $0.07-0.30, \mathrm{P}<0.001$ ), or ARV prophylaxis (OR 0.22 , 95\%CI 0.12-0.38, $\mathrm{P}<0.001)$. Among the infant correlates, age at first PCR, being exclusively breastfed, having mixed feeding and receiving ARV after birth were associated to their HIV status. It was 4 times more likely to have a positive PCR when it was done at an age beyond 6 weeks (OR $4.9,95 \%$ CI $2.67-8.83, \mathrm{P}=0.000)$. Infants on

Table II. Baseline Characteristics of the Children and the Prevention of Mother-to-Child HIV Transmission.

\begin{tabular}{lccc}
\hline Characteristics & & Frequency & Percentage \\
\hline Sex & Male & 60 & 56.1 \\
& Females & 47 & 43.9 \\
Birth weight (grams) $(\mathrm{N}=99)$ & $<2500$ & 19 & 19.2 \\
& $2500-4000$ & 71 & 71.7 \\
& $>4000$ & 9 & 9.1 \\
ARV prophylaxis $(\mathrm{N}=107)$ & Yes & 45 & 42.0 \\
& No & 62 & 58.0 \\
Age at first PCR & 6 weeks & 13 & 12.1 \\
(N=107) & 6 weeks - 6 months & 57 & 53.3 \\
& $6-18$ months & 37 & 34.6 \\
Feeding option & Exclusive breastfeeding & 31 & 29.0 \\
& Mixed feeding & 30 & 28.0 \\
& Formula feeding & 46 & 43.0 \\
\hline
\end{tabular}

ARV: antiretroviral treatment HIV: human immunodeficiency virus; PCR: polymerase chain reaction 
Table III. Maternal Socio-Demographic and Obstetric Correlate of HIV Infection: Univariate Analysis.

\begin{tabular}{|c|c|c|c|c|c|}
\hline & \multicolumn{2}{|c|}{ HIV positive, $\mathrm{n}(\%)$} & \multirow{2}{*}{$\begin{array}{l}\text { Total } \\
\mathrm{n}(\%)\end{array}$} & \multirow{2}{*}{ Odd Ratio $[95 \% \mathrm{CI}]$} & \multirow{2}{*}{$\mathrm{P}$} \\
\hline & Yes & No & & & \\
\hline \multicolumn{6}{|c|}{ Marital status of the mother } \\
\hline Living singly* & $46(16.3)$ & $236(83.7)$ & $282(32.4)$ & $1.678[1.117-2.548]$ & 0.009 \\
\hline Living as a couple** & $61(10.4)$ & $528(89.6)$ & $589(67.6)$ & & \\
\hline \multicolumn{6}{|l|}{ Maternal age } \\
\hline$<30$ Years & $68(17.1)$ & $330(82.9)$ & $398(45.7)$ & $2.293[1.508-3.486]$ & $<0.001$ \\
\hline \multicolumn{6}{|l|}{ Mode of delivery } \\
\hline Per vaginal & $101(13.4)$ & $650(86.6)$ & $751(86.2)$ & $2.952[1.265-6.889]$ & 0.004 \\
\hline Caesarean section & $6(5.0)$ & $114(95)$ & $120(13.8)$ & & \\
\hline \multicolumn{6}{|l|}{ Place of delivery } \\
\hline Home & $9(42.9)$ & $12(57.1)$ & $21(2.4)$ & $5.755[2.364-14.008]$ & $<0.001$ \\
\hline Health facility & $98(11.5)$ & $752(88.5)$ & $850(97.6)$ & & \\
\hline \multicolumn{6}{|c|}{ Prolonged rupture of membrane } \\
\hline Yes & $8(21.1)$ & $30(78.9)$ & $38(4.4)$ & $1.977[0.882-4.434]$ & 0.083 \\
\hline No & $99(11.9)$ & $734(88.1)$ & $833(95.6)$ & & \\
\hline \multicolumn{6}{|l|}{ CD4 cell count } \\
\hline$\leq 350 / \mathrm{mm}^{3}$ & $16(8)$ & $185(92)$ & $201(32.4)$ & $1.423[0.739-2.744]$ & 0.187 \\
\hline \multicolumn{6}{|c|}{ ARV treatment during pregnancy } \\
\hline HAART & $10(2.2)$ & $451(97.8)$ & $461(63.3)$ & $0.215[0.101-0.454]$ & $<0.001$ \\
\hline ARV prophylaxis*** & $25(9.4)$ & $242(90.6)$ & $267(36.7)$ & & \\
\hline
\end{tabular}

HIV: human immunodeficiency virus; ARV: antiretroviral treatment; HAART: high active antiretroviral treatment; PCR: polymerase chain reaction; CD4: Cluster of differentiation 4.

* Living singly (never been married, divorced, widow); ${ }^{* *}$ Living as a couple (married, cohabiting), ${ }^{* * *}$ Recommended ARV prophylaxis

mixed feeding were 24 times more likely to be infected than those who were on formula (OR 24.5, 95\% CI 12.31-48.83, P<0.001). On the contrary, an infant who received ARV prophylaxis at birth $(42.1 \%)$, had a protective effect (OR 0.1, 95\%CI 0.04-0.09, $\mathrm{P}<0.001$ ) against HIV infection (Table V).

\section{Discussion}

Our study was retrospective, performed on HIV exposed infants registered in the EID program during a period of 5 years; from 2009 to 2013. Many children were excluded and the PCR tests were not performed at the study site; furthermore, the results were collected by the parents. This renders our sample size less representative.

The prevalence (12.2\%) of HIV infection in the EID program was high in our study compared to $3.7 \%$ shown by Tejiokem et al. ${ }^{14}$ in two cities that included our site. Unlike ours, their study was a multicenter prospective cohort and its results were based on 2 positive PCR tests. On the contrary, our study involved patients at various stages; some of the infants were recruited just for follow up after birth. Some came already with signs of HIV infection. The prevalence was also high (18.9\%) in Brazil and the diagnosis was based on 2 detectable viral loads and persistent positive HIV serology. ${ }^{20}$ According to some authors, the confirmatory PCR2 could be left out if on the same DBS sample a PCR1 and viral load was performed. ${ }^{21}$

Concerning the adherence to the EID program, lack of partner support could be the main hindrance to PMTCT uptake. ${ }^{22-28}$ In the present study, about half $(46.7 \%)$ of the mothers were cohabiting and $40.2 \%$ were single. Married mothers, may have adequate knowledge of PMTCT, as compared to those who are not ${ }^{29}$, however, the knowledge is not often put into the practice. Our study revealed also that the 
Table IV. Infant Correlates of HIV Infection: Univariate Analysis.

\begin{tabular}{|c|c|c|c|c|c|}
\hline & \multicolumn{2}{|c|}{ HIV Positiven, (\%) } & \multirow{2}{*}{$\begin{array}{l}\text { Total } \\
\mathrm{n}(\%)\end{array}$} & \multirow{2}{*}{ Odd Ratio (95\% CI) } & \multirow{2}{*}{$\mathrm{P}$} \\
\hline & Yes & No & & & \\
\hline \multicolumn{6}{|l|}{ Age at first PCR } \\
\hline 6 Weeks & $13(4.1)$ & $307(95.9)$ & $320(36.7)$ & $4.857[2.672-8.831]$ & $<0.001$ \\
\hline$>6$ Weeks & $94(17.1)$ & $457(82.9)$ & $551(63.3)$ & & \\
\hline \multicolumn{6}{|l|}{ Infant on ARV prophylaxis } \\
\hline Yes & $45(6.0)$ & $707(94.0)$ & $752(86.3)$ & $0.059[0.037-0.094]$ & $<0.001$ \\
\hline No & $62(52.1)$ & $57(47.9)$ & $119(13.7)$ & & \\
\hline \multicolumn{6}{|l|}{ Birth weight } \\
\hline$<2500 \mathrm{~g}$ & $19(15.7)$ & $102(84.3)$ & $121(14.5)$ & $1.481[0.861-2.547]$ & 0.104 \\
\hline$\geq 2500 \mathrm{~g}$ & $80(11.2)$ & $636(88.8)$ & $716(85.5)$ & & \\
\hline \multicolumn{6}{|l|}{ Feeding option } \\
\hline Exclusive breastfeeding & $31(14.4)$ & $185(85.6)$ & $216(26.2)$ & $2.055[1.265-3.336]$ & 0.003 \\
\hline Formula & $46(7.5)$ & $564(92.5)$ & & & \\
\hline Mixed feeding & $30(66.7)$ & $15(33.3)$ & $45(6.9)$ & $24.522[12.314-48.832]$ & $<0.001$ \\
\hline Formula & $46(7.5)$ & $564(92.5)$ & $610(93.1)$ & & \\
\hline
\end{tabular}

HIV: human immunodeficiency virus; ARV: antiretroviral treatment; PCR: polymerase chain reaction

Table V. Mother and Infants' Correlates of HIV Infection in Exposed Children: Univariate and Multivariate Analysis.

\begin{tabular}{|c|c|c|c|c|}
\hline \multirow{2}{*}{ Characteristics } & \multicolumn{2}{|c|}{ Univariate Analysis } & \multicolumn{2}{|c|}{ Multivariate Analysis } \\
\hline & Odd Ratio & $\mathrm{P}$ & Adjusted Odd Ratio & $\mathrm{P}$ \\
\hline \multicolumn{5}{|l|}{ Maternal correlates } \\
\hline Marital status (couple/single) & 1.69 & 0.009 & 0.70 & 0.176 \\
\hline Age of the mothers & 2.29 & $<0.001$ & 1.01 & 0.972 \\
\hline Per vaginal delivery & 2.95 & 0.004 & 0.71 & 0.475 \\
\hline ARV (HAART/ARV prophylaxis) & 0.22 & $<0.001$ & 0.15 & $<0.001$ \\
\hline $\begin{array}{l}\text { Place of delivery : Home/Health facility } \\
\text { Infant correlates }\end{array}$ & 5.76 & $<0.001$ & 1.85 & 0.330 \\
\hline Age at first PCR $>6$ weeks & 0.06 & $<0.001$ & 0.22 & $<0.001$ \\
\hline ARV prophylaxis & 4.86 & $<0.001$ & 2.07 & 0.035 \\
\hline Exclusive breastfeeding & 2.06 & 0.003 & 0.67 & 0.155 \\
\hline Mixed feeding & 24.52 & $<0.001$ & 3.91 & 0.002 \\
\hline
\end{tabular}

ARV: Antiretroviral Treatment; HAART: High Active Antiretroviral Treatment; PCR: Polymerase Chain Reaction

risk of HIV infection was high, when the mother was less than 30 years old. In South Africa, more than half of MTCT involved young women ${ }^{30}$; although authors noticed that maternal age was not associated with HIV MTCT. ${ }^{31}$

Concerning the obstetric factors, the type of ARV regimen during pregnancy ${ }^{8,9}$, the mode and the place of delivery were associated with HIV infection in children. Per vaginal delivery has been associated with a higher risk of MTCT. 9,20 in our study, it was the main mode of delivery $(94.4 \%)$. With respect to the place of delivery, we found that the risk of the children being HIV infected was increased by 5-fold when they were born at home. Home 
delivery is characterized by the lack PMTCT interventions ${ }^{32}$ and inadequate post natal follow up of the mother-infant pair.

Children of mothers who had received HAART before pregnancy or ARV prophylaxis were at low risk of being HIV infected. We found out that the risk of being HIV positive was higher in children whose first PCR was done beyond 6 weeks of age. Other authors found the risk to be 4.8 times higher when the infant was enrolled to follow up to an age above 6 weeks. ${ }^{27,32}$ Mixed feeding exposes children to a higher risk of HIV infection. As in others studies, ignorance of the HIV status of the mothers among others factors could have influenced their feeding choices.8,9

The high rate of infection associated with the maternal and infant correlates of HIV infected children would have result ed from the poor implementation of PMTCT in our setting. Systematic screening of pregnant and breastfeeding women should be reinforced and the Option $\mathrm{B}+$ be promoted.

\section{Acknowledgements}

We thank the staff of the MCC-CBF for their collaboration.

\section{REFERENCES}

1. Newell ML, Dunn DT, Peckham CS, Semprini AE, Pardi G. Vertical transmission of HIV-1: Maternal immune status and obstetric factors. The European Collaborative Study. AIDS Lond Engl 1996; 10: 1675-1681.

2. Newell M-L. Current issues in the prevention of mother-to-child transmission of HIV-1 infection. Trans R Soc Trop Med Hyg 2006; 100: 1-5.

3. Barron P, Pillay Y, Doherty T, et al. Eliminating motherto-child HIV transmission in South Africa. Bull World Health Organ 2013; 91: 70-74.

4. Gourlay A, Birdthistle I, Mburu G, Iorpenda K, Wringe A. Barriers and facilitating factors to the uptake of antiretroviral drugs for prevention of mother-to-child transmission of HIV in sub-Saharan Africa: A systematic review. J Int AIDS Soc 2013; 16: 18588.

5. OuédraogoYugbaré SO, Zagré N, Koueta F et al. Effectiveness of Prevention of Mother to Child Transmission of Human Immunodeficiency Virus by the 2010 Protocol of the World Health Organisation at the Medical Center Saint Camille de Ouagadougou (Burkina Faso). Pan Afr Med J 2015; 22: 303.

6. Kouanda S, Tougri H, Cisse M, Simpore J et al. Impact of maternal HAART on the prevention of mother-tochild transmission of HIV: Results of an 18-month follow-up study in Ouagadougou, Burkina Faso. AIDS Care 2010; 22: 843-850.
7. Soubeiga ST, Compaore R, Djigma F et al. Evaluation of antiretroviral therapy on mother to child transmission HIV in HIV-1 positive women: Case of St. Camillus Medical Center in Ouagadougou, Burkina Faso. Pan Afr Med J 2015; 20: 399.

8. Anoje C, Aiyenigba B, Suzuki C et al. Reducing mother-to-child transmission of HIV: findings from an early infant diagnosis program in south-south region of Nigeria. BMC Public Health 2012; 12: 184.

9. Koye DN, Zeleke BM. Mother-to-child transmission of HIV and its predictors among HIV-exposed infants at a PMTCT clinic in northwest Ethiopia. BMC Public Health 2013; 13: 398.

10. Ghadrshenas A, Ben Amor Y, Chang J, et al. Improved access to early infant diagnosis is a critical part of a child-centric prevention of mother-to-child transmission agenda. AIDS 2013; 27: S197-S205.

11. WHO. Early detection of HIV infection in infants and children. Available at: www.who.int/hiv/paediatric/ EarlydiagnostictestingforHIVVer_Final_May07. 2010 (Accessed July 19, 2015)

12. Newell ML, Coovadia H, Cortina-Borja M, Rollins N, Gaillard P, Dabis F; Ghent International AIDS Society (IAS) Working Group on HIV Infection in Women and Children. Mortality of infected and uninfected infants born to HIV-infected mothers in Africa: A pooled analysis. Lancet 2004; 364: 1236-1243.

13. Brahmbhatt H, Kigozi G, Wabwire-Mangen F, et al. Mortality in HIV-infected and uninfected children of HIV-infected and uninfected mothers in rural Uganda. JAIDS J Acquir Immune Defic Syndr 2006; 41: 504-508.

14. Tejiokem MC, Faye A, Penda IC, et al. Feasibility of early infant diagnosis of HIV in resource-limited settings: the ANRS 12140-Pediacam study in Cameroon. PloS One 2011; 6: e21840.

15. Noubiap JJN, Bongoe A, Demanou SA. Mother-to-child transmission of HIV: Findings from an early infant diagnosis program in Bertoua, Eastern Cameroon. Pan Afr Med J 2013; 15: 65.

16. Nguefack F, Dongmo R, Kenfack B, Socpa A. Factors responsible of the late access to early HIV diagnosis test, in exposed infants of seropositive mothers in Yaoundé. J Pédiatrie Puériculture 2014; 27: 276-284.

17. Sherman GG, Jones SA, Coovadia AH, Urban MF, Bolton KD. PMTCT from research to reality--results from a routine service. South Afr Med J 2004; 94: 289-292.

18. Rouet F, Ekouevi DK, Chaix M-L, et al. Transfer and evaluation of an automated, low-cost real-time reverse transcription-PCR test for diagnosis and monitoring of human immunodeficiency virus type 1 infection in a West African resource-limited setting. J Clin Microbiol 2005; 43: 2709-2717.

19. Read JS, Committee on Pediatric AIDS, American Academy of Pediatrics. Diagnosis of HIV-1 infection in children younger than 18 months in the United States. Pediatrics 2007; 120: e1547-e1562.

20. de Lemos LMD, Lippi J, Rutherford GW et al. Maternal risk factors for HIV infection in infants in northeastern Brazil. Int J Infect Dis 2013; 17: e913-e918. 
21. Nkenfou CN, Lobé EE, Ouwe-Missi-Oukem-Boyer O, et al. Implementation of HIV early infant diagnosis and HIV type 1 RNA viral load determination on dried blood spots in Cameroon: Challenges and propositions. AIDS Res Hum Retroviruses 2012; 28: 176-181.

22. Auvinen J, Kylmä J, Suominen T. Male involvement and prevention of mother-to-child transmission of HIV in Sub-Saharan Africa: An integrative review. Curr HIV Res 2013; 11: 169-177.

23. Aluisio A, Richardson BA, Bosire R, John-Stewart G, Mbori-Ngacha D, Farquhar C. Male antenatal attendance and HIV testing are associated with decreased infant HIV infection and increased HIV free survival. J Acquir Immune Defic Syndr 2011; 56: 76-82.

24. Dunlap J, Foderingham N, Bussell S, Wester CW, Audet $\mathrm{CM}$, Aliyu $\mathrm{MH}$. Male involvement for the prevention of mother-to-child HIV transmission: A brief review of initiatives in East, West, and Central Africa. Curr HIV/AIDS Rep 2014; 11: 109-118.

25. Theuring S, Mbezi P, Luvanda H, Jordan-Harder B, Kunz A, Harms G. Male involvement in PMTCT services in Mbeya Region, Tanzania. AIDS Behav 2009; 13: 92-102.

26. Kalembo FW. Male partner involvement in prevention of mother to child transmission of HIV in Sub-Saharan Africa: Successes, challenges and way forward. Open J Prev Med 2012; 02: 35-42.
27. Haile F, Brhan Y. Male partner involvements in PMTCT a cross sectional study, Mekelle, Northern Ethiopia. BMC Pregnancy Childbirth 2014; 14: 65 .

28. Adelekan AL, Edoni ER, Olaleye OS. Married men perceptions and barriers to participation in the prevention of mother-to-child HIV transmission care in Osogbo, Nigeria. J Sex Transm Dis 2014; 2014: e680962.

29. Malaju MT, Alene GD. Determinant factors of pregnant mothers' knowledge on mother to child transmission of HIV and its prevention in Gondar town, North West Ethiopia. BMC Pregnancy Childbirth 2012; 12: 73 .

30. Fatti G, Shaikh N, Eley B, Jackson D, Grimwood A. Adolescent and young pregnant women at increased risk of mother-to-child transmission of HIV and poorer maternal and infant health outcomes: A cohort study at public facilities in the Nelson Mandela Bay Metropolitan district, Eastern Cape, South Africa. S Afr Med J 2015; 104: 874-880.

31. Bucagu M, Bizimana J de D, Muganda J, Humblet CP Socio-economic, clinical and biological risk factors for mother - to- child transmission of HIV-1 in Muhima health centre (Rwanda): A prospective cohort study. Arch Public Health 2013; 71: 4.

32. Lerebo W, Callens S, Jackson D, Zarowsky C, Temmerman M. Identifying factors associated with the uptake of prevention of mother to child HIV transmission programme in Tigray region, Ethiopia: A multilevel modeling approach. BMC Health Serv Res 2014; 14: 181. 